\title{
The modified Thomas test is not a valid measure of hip extension unless pelvic tilt is controlled
}

\author{
Andrew D Vigotsky ${ }^{\text {Corresp.. }}{ }^{1}$ ， Gregory J Lehman ${ }^{2}$, Chris Beardsley ${ }^{3}$, Bret Contreras ${ }^{4}$, Bryan Chung ${ }^{5}$, Erin $\mathbf{H}$ \\ Feser $^{1}$ \\ ${ }^{1}$ Kinesiology Program, Arizona State University, Phoenix, Arizona, United States \\ 2 Private Practice, Toronto, Ontario, Canada \\ 3 Strength and Conditioning Research Limited, London, United Kingdom \\ 4 School of Sport and Recreation, Auckland University of Technology, Auckland, New Zealand \\ 5 Department of Plastic Surgery, Island Health Authority, Victoria, British Columbia, Canada \\ Corresponding Author: Andrew D Vigotsky \\ Email address: avigotsky@gmail.com
}

The modified Thomas test was developed to assess the presence of hip flexion contracture and to measure hip extensibility. Despite its widespread use, to the authors' knowledge, its criterion reference validity has not yet been investigated. The purpose of this study was to assess the criterion reference validity of the modified Thomas test for measuring peak hip extension angle and hip extension deficits, as defined by the hip not being able to extend to 0 , or neutral. Twenty-nine healthy college students (age $=22.00 \pm 3.80$ years; height $=1.71 \pm 0.09 \mathrm{~m}$; body mass $=70.00 \pm 15.60 \mathrm{~kg}$ ) were recruited for this study. Bland-Altman plots revealed poor validity for the modified Thomas test's ability to measure hip extension, which could not be explained by differences in hip flexion ability alone. The modified Thomas test displayed a sensitivity of $31.82 \%(95 \% \mathrm{Cl}=13.86-54.87)$ and a specificity of $57.14 \%$ (95\% Cl $=18.41-90.10)$ for testing hip extension deficits. It appears, however, that by controlling pelvic tilt, much of this variance can be accounted for $(r=$ 0.98). When pelvic tilt is not controlled, the modified Thomas test displays poor criterion reference validity and, as per previous studies, poor reliability. However, when pelvic tilt is controlled, the modified Thomas test appears to be a valid test for evaluating peak hip extension angle. 


\section{The modified Thomas test is not a valid measure of hip extension unless pelvic tilt is} controlled

\author{
Running Head: THOMAS TEST VALIDITY
}

\author{
Andrew D. Vigotsky, BS ${ }^{1}$ \\ Gregory J. Lehman, MSc, DC, MScPT ${ }^{2}$ \\ Chris Beardsley, $\mathrm{MSc}^{3}$ \\ Bret Contreras, $\mathrm{PhD}^{4}$ \\ Bryan Chung, $\mathrm{MD}, \mathrm{PhD}^{5}$ \\ Erin H. Feser, MS ${ }^{1}$
}

${ }^{1}$ Kinesiology Program, School of Nutrition and Health Promotion, College of Health Solutions, Arizona State University, Phoenix, AZ, United States of America

${ }^{2}$ Private Practice, Toronto, ON, Canada

${ }^{3}$ Strength and Conditioning Research Limited, London, UK

${ }^{4}$ School of Sport and Recreation, Auckland University of Technology, Auckland, New Zealand

7

${ }^{5}$ Hand Program, University Health Network, Toronto, Canada 


\section{ABSTRACT}

21 The modified Thomas test was developed to assess the presence of hip flexion contracture and to

22 measure hip extensibility. Despite its widespread use, to the authors' knowledge, its criterion

23 reference validity has not yet been investigated. The purpose of this study was to assess the

24 criterion reference validity of the modified Thomas test for measuring peak hip extension angle

25 and hip extension deficits, as defined by the hip not being able to extend to $0^{\circ}$, or neutral.

26 Twenty-nine healthy college students (age $=22.00 \pm 3.80$ years; height $=1.71 \pm 0.09 \mathrm{~m}$; body

27 mass $=70.00 \pm 15.60 \mathrm{~kg}$ ) were recruited for this study. Bland-Altman plots revealed poor

28 validity for the modified Thomas test's ability to measure hip extension, which could not be

29 explained by differences in hip flexion ability alone. The modified Thomas test displayed a

30 sensitivity of $31.82 \%(95 \% \mathrm{CI}=13.86-54.87)$ and a specificity of $57.14 \%(95 \% \mathrm{CI}=18.41-$

3190.10 ) for testing hip extension deficits. It appears, however, that by controlling pelvic tilt, much

32 of this variance can be accounted for $(r=0.98)$. When pelvic tilt is not controlled, the modified

33 Thomas test displays poor criterion reference validity and, as per previous studies, poor

34 reliability. However, when pelvic tilt is controlled, the modified Thomas test appears to be a

35 valid test for evaluating peak hip extension angle.

37 INTRODUCTION

The Thomas test (TT), named after Dr. Hugh Owen Thomas, was created to rule out hip

flexion contracture (Thomas 1878), meaning that a positive TT is indicative of hip flexion contracture. Since then, it has been used ubiquitously to assess hip extensibility. The TT is a

$41 \mathrm{pass} /$ fail test in which the patient lies supine upon an examination table with both legs straight

42 out in front of them on the table top. While supine, the patient flexes the hip of one leg and 
43 holds the knee of the same leg maximally flexed at the chest. The pelvis is maintained in neutral

44 throughout. The contralateral leg is allowed to remain relaxed and flat against the tabletop. A

45 positive TT, which is taken as indicative of hip flexion contracture, is where there is noticeable

46 hip flexion of the contralateral leg, as indicated by a gap between this leg and the table top. For

47 the purposes of this study, the aforementioned hip flexion contracture will be referred to as a hip

48 extension deficit, as more than just contracture can inhibit hip extension. The modified TT

49 (MTT) is performed in a similar fashion to the original Thomas test, but is carried out at the edge

50 of the tabletop. Thus, the contralateral leg is allowed to hang down over the edge of the table,

51 which permits the measurement of a peak hip extension angle in all individuals and not just those

52 in whom there is a hip extension deficit.

53 There are numerous potential confounders with both the TT and MTT that may yield

54 them invalid for their intended purpose. Most importantly, they do not consider lumbopelvic

55 movement, hip flexion ability, waist size, or thigh circumference. Lumbopelvic movement may

56 influence the outcome of the MTT in two ways, in that anterior pelvic tilt can mimic hip

57 extension, thus rendering a false negative or inflated peak hip extension angle, or vice-versa with

58 posterior pelvic tilt. Presumably, lumbopelvic movement is at least partially due to hip flexion

59 ability of the hip contralateral to the one being tested, or how much hip flexion range of motion

60 (ROM) one possesses before his or her pelvis is forced to rotate. A restriction in hip flexion

61 ability will force a person into a posterior pelvic tilt when trying to bring his or her knee to his or

62 her chest; however, a person with substantial hip flexion ability will be able to perform

63 simultaneous anterior pelvic tilt, thus potentially rendering a false negative or inflated peak hip

64 extension angle. Waist size and thigh circumference are separate from, but have similar effects

65 as, hip flexion ability. A person with a large thigh and waist circumference may not be able to 
66 exhaust his or her hip flexion ability before his or her thigh and waist make contact, which will

67 allow for that person to utilize anterior pelvic tilt during testing.

68 Hip extension is considered to be important for the performance of various athletic

69 activities. A lack of hip extension has been theorized to lead to an overstriding gait and increased

70 impact forces during running (Derrick et al. 1998; Franz et al. 2009), which may increase the risk

71 of tibial stress fracture (Edwards et al. 2009). Further, a lack of hip extension may be associated

72 with tightness in the hip flexor muscles. A postural hypothesis related to hamstring strains is that

73 tight hip flexors lead to an anterior pelvic tilt, which may predispose sprint athletes to hamstring

74 strains (Gabbe et al. 2006). Lastly, for individuals with low back pain that is sensitive to spine

75 extension, tight hip flexors may lead these individuals to perform spinal movements that bias

76 increased spine extension, as the individual lacks movement options due to their hip extension

77 limitations.

78 The reliability of both the TT and MTT has been studied with mostly positive outcomes

79 outcomes (Aalto et al. 2005; Cejudo et al. 2015; Clapis et al. 2007; Gabbe et al. 2004; Harvey

80 1998; Heino et al. 1990; Lai et al. 2012; Parikh \& Arora 2015; Peeler \& Anderson 2007a; Peeler

81 \& Leiter 2013; Peeler \& Anderson 2007b; Petersen et al. 2015; Pua et al. 2008; Roach et al.

82 2013). However, to the authors' knowledge, only the TT has been validated, which was shown to

83 have convergent validity with maximum hip extension during stance phase of gait, hip flexor

84 index, and maximum psoas length in normal controls, but not patients with cerebral palsy (Lee et

85 al. 2011). Therefore, purpose of this investigation was to determine the criterion reference

86 validity of the MTT using more objective measures; namely, two-dimensional sagittal plane

87 motion capture measured relative to the pelvis. 


\section{METHODS}

\section{Participants}

Healthy participants were recruited from a student population via flyers placed around campus and presented to Kinesiology and Exercise and Wellness classes. Before each participant was scheduled for testing, investigators asked the participant about his or her current injury status. Participants were excluded if they had current symptoms of back or lower extremity musculoskeletal or neuromuscular injury or pain; however, participants were not excluded if they previously had a back or lower extremity musculoskeletal or neuromuscular injury but were currently symptom-free, no matter how recent symptoms may have been experienced. Participants were scheduled to come into the laboratory for one visit. Upon arrival, participants were provided a verbal explanation of the study, and read and signed an Informed Consent and Physical Activity Readiness Questionnaire (PAR-Q) before beginning. Any participant that answered "Yes" to any of the questions on the PAR-Q was excluded. The study was approved by the Institutional Review Board at Arizona State University (IRB ID: STUDY00001660).

\section{Preparation and Measurement}

After completing an Informed Consent and PAR-Q, participants' age, height, and body

mass were measured (Table 1). Thereafter, a ten-minute standardized warm up procedure

107 followed. This warm up consisted of five minutes on an Airdyne bike, two sets of 20 bodyweight

109 bodyweight lunges (Vigotsky et al. 2015).

110 Once the ten-minute warm-up was completed, reflective markers were adhered to

111 participants' skin or tight fitting garments on the iliac crest, in line with the PSIS and ASIS and 
112 spaced $10 \mathrm{~cm}$ apart, the lateral femoral epicondyle, and the greater trochanter. These methods

113 differ slightly from those presented by Kuo et al. (2008), as the PSIS and ASIS markers were

114 placed closer to the midaxillary line so as not to be blocked by the table or thigh during hip

115 flexion (Vigotsky et al. 2015) (Figure 1). True hip flexion and extension values were calculated

116 by subtracting the four-point angles these markers create from $90^{\circ}$, as described by Sprigle et al.

117 (2002) and Sprigle et al. (2003). Pelvic tilt was calculated as the angle between the intercristal

118 line (created from the ASIS to PSIS) and horizontal plane, offset by $90^{\circ}$. Two-dimensional

119 sagittal plane motion capture was obtained using an infrared camera set to $30 \mathrm{~Hz}$ (Basler Scout

120 scA640-120, Basler Vision Technologies, USA) and motion analysis software (MaxTRAQ 2D,

121 Innovision Systems Inc., USA).

122

123 [ Insert Figure 1 about here. ]

Procedures

The MTT was performed by having the participant hold his or her non-testing knee (left) to his or her chest, while letting the thigh and leg of the testing hip (right) hang freely (Harvey 1998). However, the methods utilized for measuring true hip extension (motion capture) differ substantially from those previously described (Harvey 1998), in that the hip angle was measured relative to the pelvis rather than the plinth. This prevented lumbar hyperextension, decreased hip

131 flexion ability, or large waist and thigh circumferences from confounding the results of the true

132 hip extension test. Hip extension angles could then be compared relative to the pelvis (true hip

133 extension) versus hip extension as it is typically measured with the MTT (hip extension relative

134 to the plinth). Each participant completed the MTT three times. Between each trial, the 
135 participant stood up from, and sat back down on, the plinth, as to "reset" his or her position. The

136 average of each participant's three trials was then used for analyses.

138 Statistical Analyses

139 Bland-Altman plots, with 95\% limits of agreement and 95\% confidence intervals for

140 those limits of agreement (Bland \& Altman 1986; Carkeet 2015; Sedgwick 2013), were created

141 to determine the magnitude and variability of the differences between true hip extension and the

142 MTT (that is, the angle of the thigh relative to horizontal), in addition to correlations. Pearson

143 correlation coefficients were used to explore the possible source of discrepancy between true hip

144 extension angle and the MTT, between the difference between true hip extension and the result

145 of the MTT and the following: hip flexion ROM before posterior pelvic tilt or thigh-waist

146 contact; the sum of waist and thigh circumferences; and pelvic tilt during the MTT.

147 The binary pass/fail outcome of a MTT is often determined by whether or not the thigh is 148 above horizontal (Clapis et al. 2007; Ferber et al. 2010). In order to determine the validity of the

149 MTT for determining the presence of hip extension deficits, the sensitivity, specificity, and their

$15095 \%$ confidence intervals were also determined. A test was said to be positive if, for the MTT,

151 the thigh was above parallel (that is, if the knee was higher than the hip), or if, for the true hip

152 extension test, a hip angle of $\geq 0^{\circ}$ could not be obtained.

153

\section{RESULTS}

155 Twenty-nine healthy participants were recruited for this study (Table 1). A Bland-Altman

156 plot of MTT and true sagittal plane hip extension is shown in Figure 2, and the raw data and

157 differences between the MTT and true sagittal plane hip extension can be found in Table 2. The 
158 angle of the thigh relative to horizontal was moderately correlated with sagittal plane hip

159 extension $(r=0.50)$. Correlations revealed that these differences could not be explained by hip

160 flexion ROM alone $(r=0.11)$ or waist and thigh circumferences $(r=-0.12)$. In contrast, pelvic

161 tilt was strongly associated with the difference between true hip extension and the MTT ( $r=$

162 0.98) (Figure 3). When assessing pass/fail for hip extension deficit, the MTT displayed a

163 sensitivity of $31.82 \%(95 \% \mathrm{CI}=13.86-54.87)$ and a specificity of $57.14 \%(95 \% \mathrm{CI}=18.41-$

164 90.10).

165

$166 \quad$ Insert Tables 1 and 2 about here ]

167 [ Insert Figures 2 and 3 about here ] 


\section{DISCUSSION}

169 Although the MTT is widely used in orthopedic and physiotherapy practice, its criterion

170 reference validity has not previously been investigated. In this present study, the criterion

171 reference validity of the MTT in testing hip extension was evaluated. It was found that, when

172 compared to sagittal plane motion capture, the MTT was a relatively poor measure of hip

173 extension (Figure 2). However, pelvic tilt alone likely accounts for the variance between the

174 MTT and true hip extension, suggesting that results recorded in the MTT are substantially

175 affected by pelvic tilt. Additionally, when compared with sagittal plane motion capture, the MTT

176 was also found to have poor specificity and sensitivity for determining hip extension deficits.

177 None of these findings appear to be sex-dependent (Figures $2 \& 3$ ).

178 The reported hip extension angles are not unlike those reported by Moreside \& McGill

179 (2011), who also evaluated hip extension using motion capture. The angles of the thigh relative

180 to horizontal presented by Moreside \& McGill (2011) appear to be different, though, as the

181 authors used a pressure cuff under the lumbar spine to control for lumbopelvic movement and

182 hip flexion differences. More specifically, the authors placed a blood pressure cuff, inflated to 60

$183 \mathrm{mmHg}$, under participants' lumbar spine, and if cuff pressure changed, it was indicative of

184 lumbopelvic motion. Furthermore, the authors offset the MTT results by $10^{\circ}$, which assumes

185 equal pelvic tilt is occurring for all participants. Our findings indicate that if pelvic tilt is

186 corrected for, the discrepancies between the results of the MTT, true hip extension, and the MTT

187 results reported by Moreside \& McGill (2011) should be diminished.

188 Although the MTT has previously been assumed to be a test for hip extension ROM, this

189 is not necessarily the case. ROM testing is typically performed either actively or passively; the

190 former requiring the person in question to move the joint in question actively, with moments 
191 produced by his or her muscles, while the latter implies that an external force (such as a

192 practitioner) generates a moment about the joint. In both active and passive ROM testing,

193 typically, the ROM is taken to what is perceived as "end range". However, as briefly noted by

194 Zafereo et al. (2015) and Vigotsky et al. (2015), the MTT may not reflect true ROM endpoints;

195 rather, it is posited that, because the only external force applied to the lower extremity is the

196 weight of the limb itself, the external hip extension moment should be the same for all

197 intraindividual tests. Should the hip extension moment be the same for each test, only a decrease

198 in passive stiffness of the tissue being stressed (i.e., rectus femoris) would allow for an increase

199 in the measured ROM; therefore, the MTT may be a measure of passive stiffness for one point in

200 the individual's ROM.

201 The findings of this present study are complementary to the reliability data reported by

202 Kim \& Ha (2015), who found that that the MTT is more reliable after correcting for lumbopelvic

203 movement. Such a consideration has been previously suggested by other studies (Moreside \&

204 McGill 2011), but until now, its importance has not been quantified. Moreover, the low

205 sensitivity and specificity observed in this study have remarkable clinical implications, in that

206 they suggest that practitioners who utilize the MTT to assess the presence of hip flexion

207 contracture or a hip extension deficit, without controlling for pelvic tilt, are doing so with a high

208 risk of both false positive and false negative findings. However, these data also suggest that the

209 observed sensitivity and specificity can be drastically improved by controlling for pelvic tilt

210 (Figure 3). Future studies should investigate the effects on criterion reference validity of using

211 different methods, such as palpation and inflatable cuffs, to control for pelvic tilt during the

212 MTT. 
214 extension. Other methods exist to measure pelvic tilt, or hip extension, such as forming a

215 (vertical) plane using the left and right ASIS and pubic symphysis (Kendall et al. 1993) or by

216 creating a (horizontal) plane using the ischial spine and pubic symphysis (Sinnatamby 2011).

217 Such methods have been shown to produce different results from the ASIS-PSIS references

218 utilized in this study (range $=0-23^{\circ}$; mean $\left.=13 \pm 5^{\circ}\right)$ (Preece et al. 2008). However, such

219 methods are not clinically applicable, and additionally, there is no consensus as to the exact

220 definition and position of a "neutral hip".

221

222 CONCLUSIONS

The data presented in this study suggest that the MTT is not a valid measure of hip extension unless lumbopelvic movement is controlled for. Specifically, the MTT displays poor sensitivity, specificity, and criterion reference validity relative to sagittal plane motion capture; however, much of this variance is due to pelvic tilt during the test. Due to the ubiquity of the MTT, the findings of this current study are highly relevant to the practice of musculoskeletal practitioners. It is of the utmost importance that, when utilizing the MTT, practitioners control 
233

234

235

236

237

238

239

240

241

242

243

244

245

246

247

248

249

250

251

252

253

254

255

256

257

258

259

260

261

262

263

264

265

266

267

268

269

270

271

272

273

274

275

276

\section{References}

Aalto TJ, Airaksinen O, Harkonen TM, and Arokoski JP. 2005. Effect of passive stretch on reproducibility of hip range of motion measurements. Archives of Physical Medicine and Rehabilitation 86:549-557. 10.1016/j.apmr.2004.04.041

Bland JM, and Altman DG. 1986. Statistical methods for assessing agreement between two methods of clinical measurement. Lancet 1:307-310.

Carkeet A. 2015. Exact parametric confidence intervals for bland-altman limits of agreement. Optometry and Vision Science 92:e71-80. 10.1097/OPX.0000000000000513

Cejudo A, Sainz de Baranda P, Ayala F, and Santonja F. 2015. Test-retest reliability of seven common clinical tests for assessing lower extremity muscle flexibility in futsal and handball players. Physical Therapy in Sport 16:107-113. 10.1016/j.ptsp.2014.05.004

Clapis PA, Davis SM, and Davis RO. 2007. Reliability of inclinometer and goniometric measurements of hip extension flexibility using the modified Thomas test. Physiotherapy Theory and Practice 24:135-141. 10.1080/09593980701378256

Derrick TR, Hamill J, and Caldwell GE. 1998. Energy absorption of impacts during running at various stride lengths. Medicine and Science in Sports and Exercise 30:128-135.

Edwards WB, Taylor D, Rudolphi TJ, Gillette JC, and Derrick TR. 2009. Effects of stride length and running mileage on a probabilistic stress fracture model. Medicine and Science in Sports and Exercise 41:2177-2184. 10.1249/MSS.0b013e3181a984c4

Ferber R, Kendall KD, and McElroy L. 2010. Normative and critical criteria for iliotibial band and iliopsoas muscle flexibility. Journal of Athletic Training 45:344-348. 10.4085/10626050-45.4.344

Franz JR, Paylo KW, Dicharry J, Riley PO, and Kerrigan DC. 2009. Changes in the coordination of hip and pelvis kinematics with mode of locomotion. Gait and Posture 29:494-498. 10.1016/j.gaitpost.2008.11.011

Gabbe BJ, Bennell KL, and Finch CF. 2006. Why are older Australian football players at greater risk of hamstring injury? Journal of Science and Medicine in Sport 9:327-333. 10.1016/j.jsams.2006.01.004

Gabbe BJ, Bennell KL, Wajswelner H, and Finch CF. 2004. Reliability of common lower extremity musculoskeletal screening tests. Physical Therapy in Sport

Harvey D. 1998. Assessment of the flexibility of elite athletes using the modified Thomas test. British Journal of Sports Medicine 32:68-70.

Heino JG, Godges JJ, and Carter CL. 1990. Relationship between Hip Extension Range of Motion and Postural Alignment. Journal of Orthopaedic and Sports Physical Therapy 12:243-247.

Kendall FP, McCreary EK, Provance PG, Rodgers MM, and Romani W. 1993. Muscles, testing and function: with posture and pain.

Kim GM, and Ha SM. 2015. Reliability of the modified Thomas test using a lumbo-plevic stabilization. Journal of Physical Therapy Science 27:447-449. 10.1589/jpts.27.447

Kuo Y-LL, Tully EA, and Galea MP. 2008. Skin movement errors in measurement of sagittal lumbar and hip angles in young and elderly subjects. Gait and Posture 27:264-270. 10.1016/j.gaitpost.2007.03.016

Lai WH, Shih YF, Lin PL, Chen WY, and Ma HL. 2012. Normal neurodynamic responses of the femoral slump test. Manual Therapy 17:126-132. 10.1016/j.math.2011.10.003 
277

278

279

280

281

282

283

284

285

286

287

288

289

290

291

292

293

294

295

296

297

298

299

300

301

302

303

304

305

306

307

308

309

310

311

312

313

314

315

316

317

318

319

320

321

322

Lee KM, Chung CY, Kwon DG, Han HS, Choi IH, and Park MS. 2011. Reliability of physical examination in the measurement of hip flexion contracture and correlation with gait parameters in cerebral palsy. Journal of Bone and Joint Surgery (American Volume) 93:150-158. 10.2106/JBJS.J.00252

Moreside JM, and McGill SM. 2011. Quantifying normal 3D hip ROM in healthy young adult males with clinical and laboratory tools: hip mobility restrictions appear to be planespecific. Clinical Biomechanics (Bristol, Avon) 26:824-829. 10.1016/j.clinbiomech.2011.03.015

Parikh CM, and Arora M. 2015. Establishing Normal Values for Lower Extremity Muscle Length and comparison of muscle length from dominant to non dominant side in Elite Cricketers aged 15-22 years. IJTRR 4:1-15.

Peeler J, and Anderson JE. 2007a. Reliability of the Thomas test for assessing range of motion about the hip. Physical Therapy in Sport 8:14-21. 10.1016/j.ptsp.2006.09.023

Peeler J, and Leiter J. 2013. Using digital photography to document rectus femoris flexibility: A reliability study of the modified Thomas test. Physiotherapy Theory and Practice 29:319327. 10.3109/09593985.2012.731140

Peeler JD, and Anderson JE. 2007b. Reliability limits of the modified Thomas test for assessing rectus femoris muscle flexibility about the knee joint. Journal of Athletic Training 43:470-476. 10.4085/1062-6050-43.5.470

Petersen N, Thieschafer L, Ploutz-Snyder L, Damann V, and Mester J. 2015. Reliability of a new test battery for fitness assessment of the European Astronaut corps. Extrem Physiol Med 4:12. 10.1186/s 13728-015-0032-y

Preece SJ, Willan P, Nester CJ, Graham-Smith P, Herrington L, and Bowker P. 2008. Variation in pelvic morphology may prevent the identification of anterior pelvic tilt. Journal of Manual \& Manipulative Therapy 16:113-117.

Pua YH, Wrigley TV, Cowan SM, and Bennell KL. 2008. Intrarater test-retest reliability of hip range of motion and hip muscle strength measurements in persons with hip osteoarthritis. Archives of Physical Medicine and Rehabilitation 89:1146-1154. 10.1016/j.apmr.2007.10.028

Roach S, San Juan JG, Suprak DN, and Lyda M. 2013. Concurrent validity of digital inclinometer and universal goniometer in assessing passive hip mobility in healthy subjects. International Journal of Sports Physical Therapy 8:680-688.

Sedgwick P. 2013. Limits of agreement (Bland-Altman method). BMJ 346:f1630. 10.1136/bmj.f1630

Sinnatamby CS. 2011. Last's anatomy: regional and applied: Elsevier Health Sciences.

Sprigle S, Flinn N, Wootten M, and McCorry S. 2003. Development and testing of a pelvic goniometer designed to measure pelvic tilt and hip flexion. Clinical Biomechanics (Bristol, Avon) 18:462-465.

Sprigle S, Wootten M, Bresler M, and Flinn N. 2002. Development of a noninvasive measure of pelvic and hip angles in seated posture. Archives of Physical Medicine and Rehabilitation 83:1597-1602.

Thomas HO. 1878. Diseases of the Hip, Knee, and Ankle Joints: With Their Deformities, Treated by a New and Efficient Method. London: HK Lewis.

Vigotsky AD, Lehman GJ, Contreras B, Beardsley C, Chung B, and Feser EH. 2015. Acute effects of anterior thigh foam rolling on hip angle, knee angle, and rectus femoris length in the modified Thomas test. PeerJ 3:e1281. 10.7717/peerj.1281 
323 Zafereo J, Devanna R, Mulligan E, and Wang-Price S. 2015. Hip stiffness patterns in lumbar 324 flexion- or extension-based movement syndromes. Archives of Physical Medicine and 325 Rehabilitation 96:292-297. 10.1016/j.apmr.2014.09.023

326 


\section{Table 1 (on next page) \\ Descriptive statistics of participants.}

Age, height, and body mass are presented as mean \pm SD. 
1 Table 1. Descriptive statistics of participants

\begin{tabular}{|l|l|l|l|l|}
\hline Sex & n & Age (years) & Height (m) & Body mass (kg) \\
\hline Male & 11 & $22.18 \pm 4.14$ & $1.79 \pm 0.06$ & $85.00 \pm 10.00$ \\
\hline Female & 18 & $21.80 \pm 3.68$ & $1.65 \pm 0.06$ & $60.71 \pm 10.02$ \\
\hline Total & 29 & $22.00 \pm 3.80$ & $1.71 \pm 0.09$ & $70.00 \pm 15.60$ \\
\hline
\end{tabular}

2 Age, height, and body mass are presented as mean $\pm S D$. 


\section{Table 2 (on next page)}

Raw values of, and differences between, true hip extension and the MTT.

True $=$ true hip extension; $\mathbf{M T T}=$ modified Thomas test $\boldsymbol{\Delta}=$ MTT - True 
1 Table 2. Raw values of, and differences between, true hip extension and the MTT

\begin{tabular}{|c|c|c|c|c|}
\hline & Sex & True $\left(^{\circ}\right)$ & MTT ( $\left.{ }^{\circ}\right)$ & $\Delta\left(^{0}\right)$ \\
\hline 1 & $\mathrm{~F}$ & -1.1 & 19.4 & 20.5 \\
\hline 2 & $\mathrm{~F}$ & 5.3 & 9.5 & 4.1 \\
\hline 3 & $\mathrm{M}$ & -3.5 & -2.9 & 0.6 \\
\hline 4 & $\mathrm{~F}$ & 2.7 & 8.5 & 5.8 \\
\hline 5 & $\mathrm{M}$ & 4.0 & 5.0 & 1.0 \\
\hline 6 & $\mathrm{~F}$ & -5.3 & -4.5 & 0.8 \\
\hline 7 & $\mathrm{~F}$ & 3.6 & 8.9 & 5.2 \\
\hline 8 & $\mathrm{M}$ & 20.5 & 14.7 & -5.8 \\
\hline 9 & $\mathrm{M}$ & -4.5 & -10.1 & -5.6 \\
\hline 10 & $\mathrm{~F}$ & -0.6 & 2.3 & 2.9 \\
\hline 11 & $\mathrm{M}$ & 17.0 & -15.4 & -32.4 \\
\hline 12 & $\mathrm{M}$ & -5.5 & 1.1 & 6.5 \\
\hline 13 & $\mathrm{~F}$ & -4.5 & -5.7 & -1.1 \\
\hline 14 & $\mathrm{M}$ & -3.1 & 12.3 & 15.5 \\
\hline 15 & $\mathrm{~F}$ & 16.3 & 11 & -5.3 \\
\hline 16 & $\mathrm{~F}$ & 10.8 & 1 & -9.8 \\
\hline 17 & $\mathrm{~F}$ & 2.7 & -1.0 & -3.7 \\
\hline 18 & $\mathrm{~F}$ & 10.2 & 12.9 & 2.7 \\
\hline 19 & $\mathrm{~F}$ & 8.9 & 7.1 & -1.8 \\
\hline 20 & $\mathrm{~F}$ & 12.1 & 6 & -6.1 \\
\hline 21 & $\mathrm{~F}$ & 9.2 & 15.7 & 6.5 \\
\hline 22 & $\mathrm{~F}$ & 5.2 & 6.9 & 1.7 \\
\hline 23 & $\mathrm{~F}$ & -3.6 & -10.2 & -6.6 \\
\hline 24 & $\mathrm{M}$ & 12.1 & 2.1 & -10.1 \\
\hline 25 & $\mathrm{M}$ & -21.1 & -19.2 & 2.0 \\
\hline 26 & $\mathrm{~F}$ & 11.3 & -6.4 & -17.7 \\
\hline 27 & $\mathrm{M}$ & -10.7 & -10.9 & -0.2 \\
\hline 28 & $\mathrm{M}$ & 0.3 & 3.5 & 3.2 \\
\hline 29 & $\mathrm{~F}$ & 12.9 & 18.4 & 5.5 \\
\hline $\bar{x}$ & & $3.5 \pm 9.2$ & $2.8 \pm 10.1$ & $0.7 \pm 9.7$ \\
\hline
\end{tabular}

2 True $=$ true hip extension; MTT $=$ modified Thomas test; $\boldsymbol{\Delta}=$ MTT - True

3

4 


\section{Figure 1 (on next page)}

Hip extension calculations.

The illustrated participant would have a hip extension angle of $8.1^{\circ}\left(98.1^{\circ}-90^{\circ}\right)$. Illustration credit: ji Sung Kim. From Vigotsky et al. (2015) . 


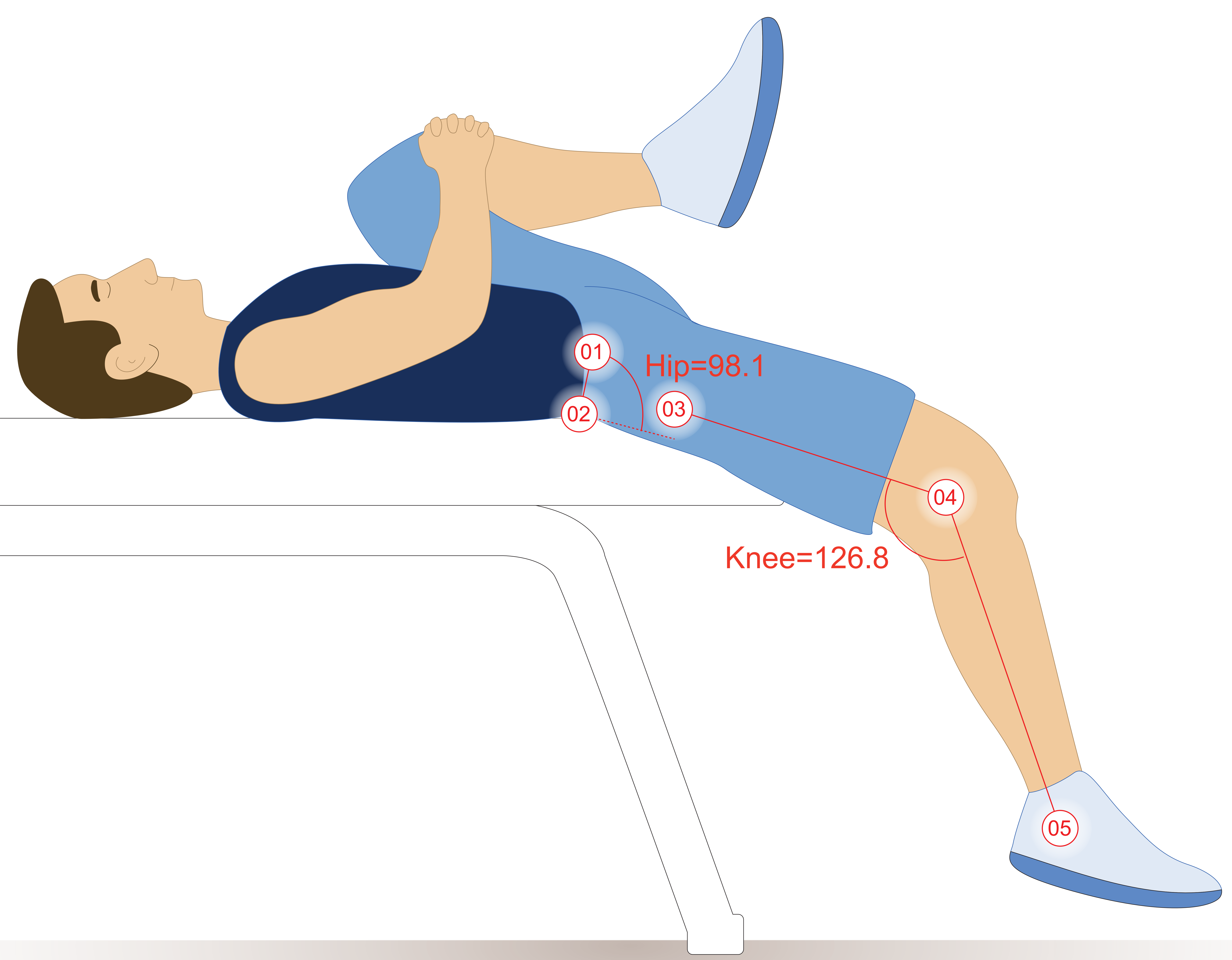




\section{Figure 2 (on next page)}

Bland-Altman plot of true hip extension and the modified Thomas test.

A mean difference of $0.7 \circ$, with $95 \%$ limits of agreements of $-18.3^{\circ}-19.7 \circ$, was found between the modified Thomas test and true hip extension. The black, solid line is indicative of the mean difference, whereas the black, dashed lines are indicative of the $95 \%$ limits of agreement. The blue, diagonal lines represent the $95 \%$ confidence intervals of the $95 \%$ limits of agreement.

MTT = modified Thomas test; pink = female; blue $=$ male 


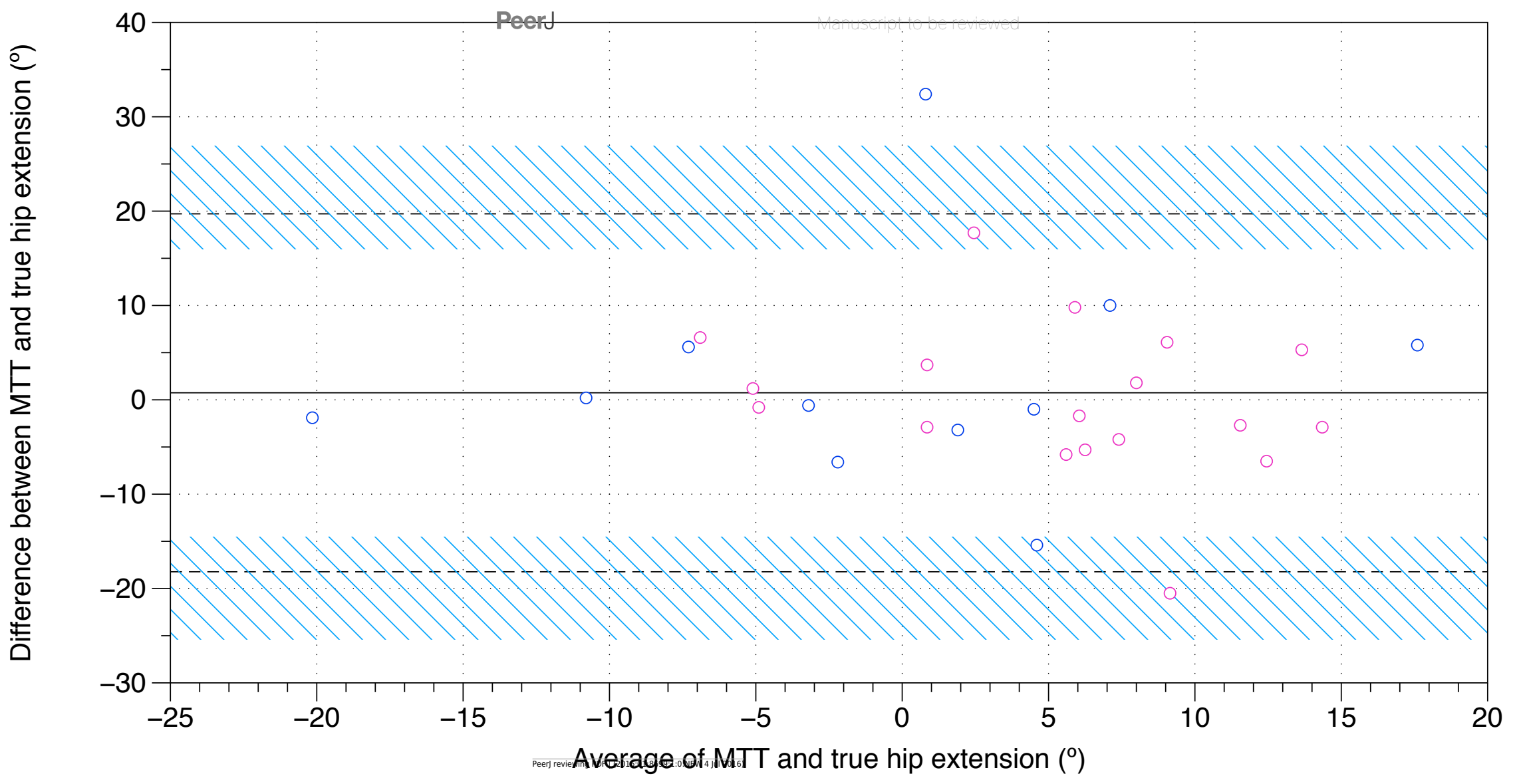




\section{Figure 3 (on next page)}

Difference between the modified Thomas test and true hip extension versus pelvic tilt during the modified Thomas test.

$(-)=$ posterior pelvic tilt; $(+)=$ anterior pelvic tilt; Difference $=$ modified Thomas test true hip extension; $\mathbf{p i n} \mathbf{k}=$ female; blue $=$ male 


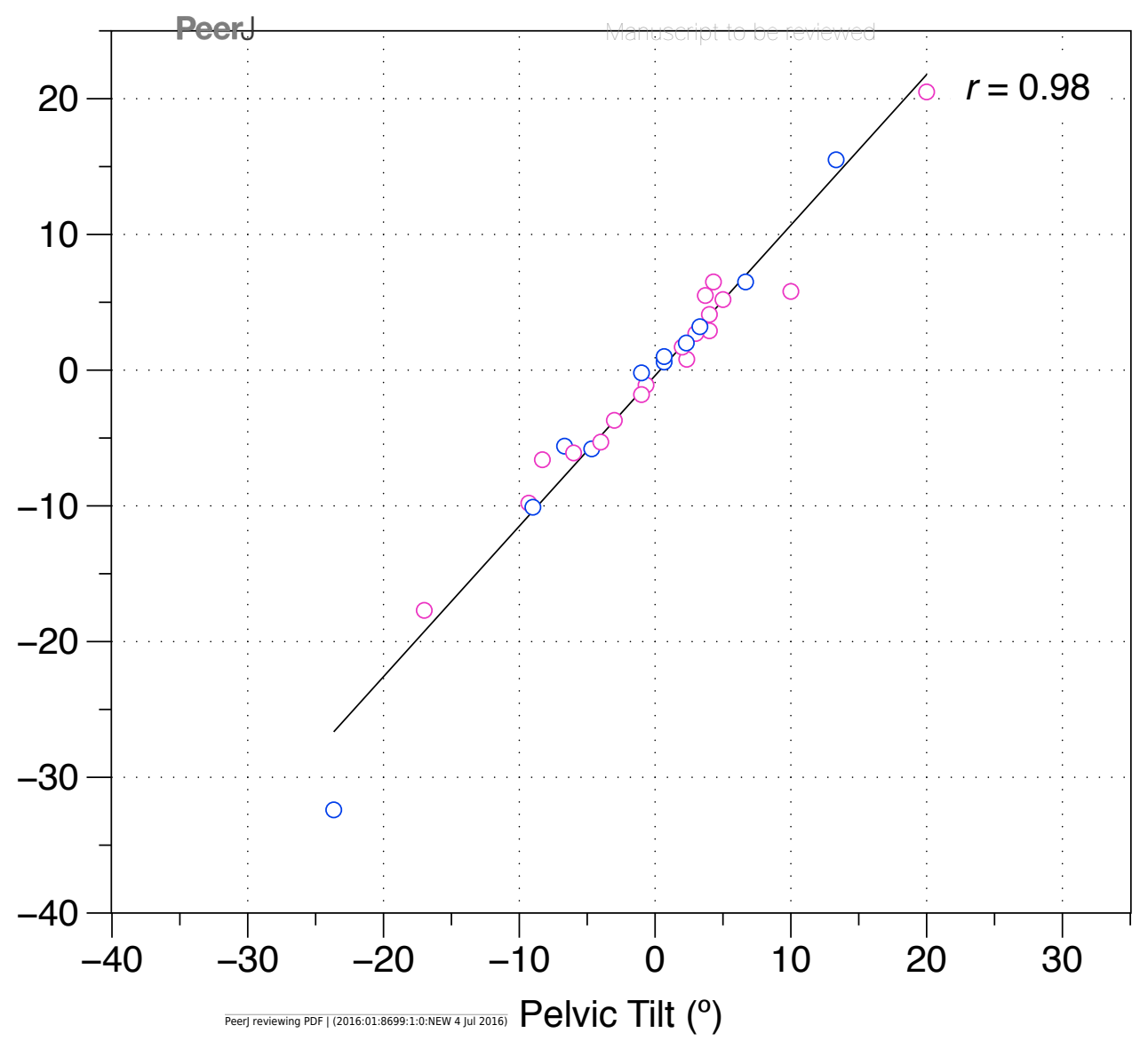

